\title{
A LEGITIMAÇÃO DA INTOLERÂNCIA NAS DECLARAÇÕES DO PASTOR SILAS MALAFAIA
}

\author{
$*$ \\ Celso Gabatz \\ Universidade do Vale do Rio dos Sinos - UNISINOS - Brasil
}

Resumo

A lógica que configura a composição do quadro doutrinário neopentecostal supõe uma nova cartografia discursiva marcada pela fragmentação das subjetividades. Enseja uma compreensão capaz de abarcar uma religiosidade que concebe o mundo em tensão permanente entre os espíritos ou demônios causadores do mal e da desordem e os deuses associados ao bem e a ordem. A religiosidade neopentecostal se articula e amolda, em grande medida, com base em um discurso acusatório que deriva dessa sua capacidade de tocar, atingir, incorporar e reorientar alguns elementos presentes no universo simbólico de referência da população brasileira. A intolerância religiosa se delineia através da batalha espiritual já não mais circunscrita à esfera espiritual, mas, cotidianamente, exacerbada pelos discursos beligerantes, sobretudo em relação ao homossexualismo e ao aborto, como os protagonizados pelo pastor Silas Malafaia. $\mathrm{O}$ artigo pretende aprofundar a perspectiva dos direitos humanos, as questões inerentes às minorias e grupos vulneráveis, o preconceito suscitado pela violência simbólica e a retórica do preconceito alicerçado pela crítica pública com nuances fundamentalistas.

Palavras-chave: Neopentecostalismo; Intolerância; Silas Malafaia.

\section{Introdução}

A relação entre diversidade sexual e religião sempre foi polêmica, controvertida e plural. Para determinados grupos religiosos, como por exemplo, os segmentos minoritários do protestantismo histórico, os cultos afro-brasileiros e algumas filosofias orientais, a diversidade sexual acabou sendo incorporada e assumida como elemento importante nas suas demandas de luta e defesa doutrinária. Já em certos setores hegemônicos do cristianismo foi se consolidando uma visão conservadora em relação a gays, lésbicas, bissexuais, travestis e transexuais ${ }^{1}$ ainda que seja possível identificar uma pluralização de opiniões, percepções e formas de atuação a partir de novas possibilidades, como por exemplo, a criação de igrejas inclusivas ou igrejas gays em vários estados brasileiros. (NATIVIDADE, 2010).

\footnotetext{
${ }^{1}$ O termo LGBT (lésbicas, gays, bissexuais, travestis, transexuais e transgêneros) foi aprovado na $1^{\text {a }}$ Conferência Nacional realizada em Brasília em junho de 2008. A mudança de nomenclatura (antes mais conhecida a partir da definição GLS) foi realizada a fim de valorizar as lésbicas no contexto da diversidade sexual, e também de aproximar o termo brasileiro com o predominante em várias outras culturas (OLIVEIRA; PICHLER; CANABARRO, 2012).
} 
Esta complexidade entre religião e sociedade, do ponto de vista dos direitos humanos, com o surgimento de novos sujeitos, sugere a ampliação dos debates onde as instituições religiosas são convidadas a repensar valores, posicionamentos, atitudes (GUERRIERO, 2006). A regulação das sexualidades pelas diretrizes religiosas de caráter fundamentalista implica na recusa de modelos igualitários de gênero, exacerba a difusão de uma mensagem sexista e emoldura visões estigmatizadas da homossexualidade (MACHADO; PICOLO, 2011). Torna-se, portanto, imperioso compreender os sentidos da rejeição de políticas inclusivas e as reivindicações por direitos de minorias sexuais, para perceber os dilemas e incoerências que conectam homofobia, convenções e valores sociais e religiosos.

As prerrogativas que suscitam o discurso legitimador da homofobia religiosa, que almeja, por exemplo, a cura da homossexualidade com sucessivos apelos à conversão acompanhados de exortações teológicas de cunho fundamentalista, revela uma preocupação com as "inversões de gênero", expressas na necessidade de tornar certos homens mais masculinos e certas mulheres mais femininas, para em última análise, usufruírem, da bondade divina e não serem "condenados". O debate acerca da legitimidade das propostas de cura da homossexualidade só poderá ser entendido quando orientar a sua visão crítica no sentido de perceber as dimensões de normatização do gênero (LOURO, 2007).

Os evangélicos neopentecostais mesmo sendo minoria em relação ao total da população brasileira, tem ocupado um lugar estratégico e de muita visibilidade. Esta inserção não decorre apenas pelo proselitismo bastante incisivo, mas em grande medida pela sua atuação na esfera pública, com destaque para a mídia e a política (EMMERICK, 2013, p. 21-78). São, portanto, atores que contribuem para amplificar as tensões da modernidade e dar à religião um novo lugar.

A afirmação da "heterossexualidade" como única forma legítima de exercício do desejo, confere importância ao "sexo" biológico, tomando diferenças de gênero e subordinações culturalmente constituídas como se fossem 'naturais' (BUTLER, 2003, p. 40-43). Consolida-se uma compreensão que sugere uma diferença indesejável capaz de ameaçar as fantasias de identidade cultivadas por alguns sujeitos que entendem que a humanidade deveria ser heterossexual.

\section{Silas Malafaia - Um Esboço Biográfico}

Silas Malafaia é pastor com formação teológica pelo Instituto Bíblico Pentecostal e psicologia pela Universidade Gama Filho, no Rio de Janeiro (MALAFAIA, 2012). Emergiu no cenário brasileiro como liderança de uma das denominações mais conhecidas do âmbito pentecostal, 
a Assembleia de Deus. ${ }^{2}$ Não se notabilizou tanto por abraçar os princípios da Teologia da Prosperidade $e^{3}$ ou combater as religiões de matriz africana, mas em função do seu estilo polemista e sua retórica belicosa, sobretudo em relação aos movimentos LGBT. Seu linguajar incisivo ao discursar não esconde sua intolerância à divergência e a opiniões contrárias. É frequente vê-lo usar os programas de televisão para disparar impropérios a outros líderes protestantes.

Defender a fé cristã e os princípios e valores éticos, morais e espirituais da Igreja de Jesus Cristo. Este tem sido o objetivo do pastor Silas Malafaia, que desde a sua juventude tem sido um incansável propagador do Evangelho, sendo reconhecido atualmente no Brasil e no exterior por seu ministério frutífero e expressivo até mesmo no meio secular (VITORIA EM CRISTO, 2014).

Malafaia assumiu no ano de 2010 a direção da Igreja Assembleia de Deus na Penha, no Rio de Janeiro, atual Assembleia de Deus Vitória em Cristo. Conta hoje com mais de 15.000 mil membros. Em pouco mais de três anos sob a sua liderança já foram criadas mais de 200 igrejas em todo o estado do Rio de Janeiro, Minas Gerais, Espírito Santo, Pernambuco, Paraná, Rio Grande do Norte, Santa Catarina (VITORIA EM CRISTO, 2014).

A Associação Vitória em Cristo, braço jurídico da denominação, sustenta um ministério atuante em segmentos para a divulgação do evangelho, nas áreas televisiva, editorial e fonográfica. Malafaia marca presença na televisão com o programa Vitória em Cristo, exibido há 30 anos em rede nacional, mas que também é de alcance internacional com transmissão para os Estados Unidos, Europa e África. Organiza eventos de repercussão como o Congresso Pentecostal Brasileiro Fogo para o Brasil, Congresso de Avivamento Despertai, a Cruzada Vida Vitoriosa e a Escola de Líderes da Associação Vitória em Cristo, onde almeja difundir a sua mensagem para um grande número de pessoas por todo o Brasil.

Silas Malafaia mantém a Editora Central Gospel, a gravadora Central Gospel Music e o portal Verdade Gospel. É vice-presidente do Conselho de Ministros Evangélicos do Brasil (CIMEB), entidade que agrega mais de 8,5 mil pastores. Já foi homenageado com o título de Cidadão Benemérito do Estado do Rio de Janeiro e a Medalha do Pacificador, entregue pelo Exército Brasileiro. Uma reportagem da revista norte-americana Forbes em 2013 o classificou como o terceiro pastor mais rico do Brasil, com um patrimônio estimado em 150 milhões de dólares (UOL, 2013).

\footnotetext{
${ }^{2}$ O sociólogo Paul Freston destaca que a Igreja Assembleia de Deus tem passado por um processo de ascensão social com uma acentuada preocupação com a respeitabilidade social e orgulho nos êxitos educacionais e profissionais dos seus membros. Há um distanciamento de grupos neopentecostais. No entanto, vive em seu cotidiano um paradoxo: permanecer ligada as virtudes doutrinárias que a instituíram e consolidaram no passado ou buscar uma reestruturação que lhe permita a permanência e adesão de novos membros (FRESTON, 1996, p. 67-99).

${ }^{3}$ A Teologia da Prosperidade também é conhecida internacionalmente a partir de uma terminologia que a retrata como confissão positiva, palavra da fé, movimento da fé, ou ainda, evangelho da saúde e prosperidade. Surgiu no início do século XX nos Estados Unidos. Sua base teórica e doutrinal encontra-se alicerçada na interpretação de determinados textos bíblicos como, por exemplo, Gênesis 17.7, Marcos 11.23-24 e Lucas 11.9-10. A Teologia da Prosperidade parte do princípio de que todos são filhos e filhas de Deus, e que, portanto, recebem os benefícios desta filiação em forma de riqueza, livramento de acidentes e catástrofes, ausência de doenças, ausência de problemas, posições de destaque, etc. Esta "teologia" oferece fórmulas para fazer o dinheiro render mais, evitar acidentes, livrar-se de doenças e problemas, aumentar as propriedades, além de viver uma vida sem dificuldades. Sustenta que nenhum filho de Deus pode adoecer ou sofrer, pois isso seria uma clara demonstração de ausência de fé e, por outro lado, da presença do diabo. Ao mesmo tempo, se chega ao exagero de declarar que quem morre antes de 70 anos é uma prova de incredulidade, imaturidade espiritual ou pecado. (MARIANO, 1999, p. 147-160).
} 
É conhecido por suas manifestações polêmicas através de textos e vídeos em que se posiciona de forma extremamente crítica em relação a temas como o aborto e a homossexualidade. Em 2008, liderou uma manifestação diante do congresso nacional, contra o projeto de Lei PLC $122^{4}$. Sua alegação era de que o mesmo não estaria protegendo os direitos dos homossexuais, mas sim lhes dando privilégios, pois suas condutas não poderiam ser mais criticadas. Ao se referir ao projeto em questão fez menção ao fato de que este seria a "primeira porta para a pedofilia" (VITÓRIA EM CRISTO, 2014).

Como um dos organizadores da Marcha para Jesus, tem se notabilizado por pautar suas falas neste espaço com uma crítica incisiva à aprovação legal da união estável entre pessoas do mesmo sexo. Foi denunciado ao Ministério Público por suas declarações homofóbicas e de incitação à violência em relação aos homossexuais (RONCAGLIA, 2012).

Em fevereiro de 2013, durante uma entrevista concedida ao programa de De Frente com Gabi, Malafaia causou forte polêmica ao afirmar que não acreditava que dois homens e duas mulheres teriam a capacidade de criar um ser humano. Reiterou que na sua denominação, pastores homossexuais, perdem o cargo. Referiu não ter nada contra homossexuais, pois "amava homossexuais assim como amava bandidos" (TOLIPAN, 2013).

O Conselho Federal de Psicologia publicou uma nota repreendendo a posição do pastor. De acordo com o referido Conselho, o mesmo "agrediu a perspectiva dos direitos humanos a uma cultura de paz e de uma sociedade que contemple a diversidade e o respeito à livre orientação", também lamentou seu discurso, explicando que a visão atual da psicologia é a de que a homossexualidade não é doença, desvio ou perversão. "É lamentável que exista um profissional que defenda uma posição de retrocesso que chega a ser quase inquisitória, colocando como vertentes do seu pensamento a exclusão e o preconceito na leitura dos direitos humanos" (CONSELHO DE PSICOLOGIA, 2013).

Para Malafaia os principais inimigos da sociedade e da moral cristã são aqueles que laboram pela dissolução da família nuclear tradicional, como os movimentos feministas e em defesa dos direitos dos homossexuais ou grupos taxados por ele, pejorativamente, de comunistas (VERDADE GOSPEL, 2012). Sua mensagem triunfalista está profundamente ligada a uma ferrenha crítica aos ideais de vida cristã e de vida secular, em que prevaleceriam o egoísmo, o individualismo, o consumismo e a cobiça. Nas suas pregações exorta um modelo de identidade cristã na qual o indivíduo deve saber viver no mundo conforme princípios cristãos, buscando sempre a santificação, o conhecimento contínuo da Bíblia e a ascensão social para ser uma pessoa e um profissional cada vez mais aperfeiçoado.

\section{Intolerância Pastoral e Regulação da (s) Sexualidade (s)}

Se ao longo da história houve diversos movimentos importantes pela produção de novos valores, por mudanças de mentalidade, influenciando a transformação das instituições e reordenando a vida social (CASTELLS, 2013). Contraditoriamente, o ativismo religioso, como defendido por Malafaia, busca a manutenção de condutas, valendo-se da autonomia de comunicação que a sociedade em rede permite.

De acordo com Boaventura de Sousa Santos (2014), para além do uso das redes móveis para coordenar ações, outro componente do processo comunicativo é a construção de um espaço público no espaço urbano. Algo que é perseguido pelos coletivos religiosos, que ocupam postos e lugares simbólicos, conseguindo colocar contingentes substanciais em protestos nas ruas e conquistando a adesão para suas comunidades mesmo de quem não tem filiação religiosa.

\footnotetext{
${ }^{4}$ Define e reitera punição aos crimes de ódio e intolerância resultantes de discriminação ou preconceito de raça, cor, etnia, religião, origem, gênero, sexo, orientação sexual, identidade de gênero ou condição de pessoa idosa ou com deficiência. Disponível em: http://www.plc122.com.br/plc122-paim/\#ixzz35rz6A2A2. Acesso em: 20 de Dez. 2015.
} 
Na opinião de Jurkewicz (2005), é possível identificar pelo menos três posicionamentos diferentes no âmbito da fé cristã frente à homossexualidade na sociedade contemporânea. $\mathrm{O}$ primeiro é de rechaço total encontrado entre aqueles que interpretam a homossexualidade como uma conduta antinatural e pecaminosa. Embora associe a conduta homossexual à perversão, esse grupo tende a defender o acolhimento na igreja daqueles que reconhecem a necessidade de mudar o comportamento. Uma segunda postura considera a conduta homossexual como aceitável, embora inferior, sugerindo àqueles que não conseguirem se ajustar ao estilo de vida heterossexual, nem manter abstinência, que devem canalizar sua atividade sexual em uma relação estável. E, a terceira, reconhece a homossexualidade tão digna como a heterossexualidade, afirmando que o pecado não está na homossexualidade em si, mas na exploração dos parceiros, fenômeno que pode ocorrer também nas relações heterossexuais.

A atuação incisiva de lideranças evangélicas para atuar nos espaços decisórios do Estado brasileiro reflete algumas questões importantes para o debate democrático e os direitos das minorias LGBT no contexto brasileiro contemporâneo (CUNHA e LOPES, 2013). Caberia perguntar acerca da possibilidade de conciliação entre a garantia da laicidade e a defesa e proteção dos direitos humanos e também a efetivação dos direitos fundamentais através da pregação de lideranças evangélicas investidas ou não de mandatos parlamentares (BEATY, 2014). As opiniões deveriam influenciar os debates relacionados às políticas públicas e à elaboração legislativa em um Estado laico?

Os discursos de lideranças evangélicas, a exemplo de Silas Malafaia, não se limitam a desqualificar a prática homossexual internamente às suas igrejas e seus fiéis. Sua atuação é voltada a influenciar as posições do Estado, seja para bloquear proposições legislativas que reconheçam direitos civis, seja na oposição de políticas governamentais de promoção da cidadania e dos direitos humanos (CÉSAR, 2013, p. 167-184).

Ao se opor a leis que incidam sobre a discriminação de pessoas em razão da sua orientação sexual ou identidade de gênero, os argumentos utilizados pelos pastores e parlamentares evangélicos são diretamente derivados de sua leitura bíblica e da moral de suas igrejas. Não procuram sustentar essa posição em termos laicos ou universalizáveis para o conjunto da população que não compartilha da mesma fé religiosa (MACHADO, 2012).

É importante aprofundar o debate e compreender com maior perspicácia se argumentos do âmbito pessoal no tocante à moral religiosa deveriam ser considerados de forma tão incisiva para o reconhecimento de direitos em um Estado laico? Cabe observar que a moral de uma sociedade democrática deveria ser crítica e não estar apenas apoiada em determinadas tradições, ainda que majoritárias. Como indicado por Roger Raupp Rios:

\footnotetext{
A convicção religiosa alheia, não pode, portanto, privar de direitos um grupo social que não se recusa a cumprir os deveres gerais da cidadania. Além de serem livres para crer, os cidadãos brasileiros são livres para não serem privados de direitos por grupos religiosos terem feitos leis fundadas em suas convicções religiosas. Dizer, portanto, que não se estendem a certos grupos (como gays e lésbicas) direitos que existem para outros pela "índole religiosa" da maioria ou pelo "direito natural" de caráter revelado ou pseudocientífico (...) é contrariar diretamente o direito constitucional (RIOS, 2011, p.39).
}

De acordo com Claude Geffré (2004), o pluralismo religioso é um aspecto essencial da experiência histórica dos tempos contemporâneos. Vivemos a era das pluralidades. Esta pluralidade ultrapassou os limites sociais. As religiões podem despertar sentimentos intensos e comportamentos radicais. 
É à luz deste pluralismo religioso que somos convidados a reinterpretar algumas verdades fundamentais do cristianismo. Se podemos falar de uma virada hermenêutica da teologia, é em grande parte porque o pluralismo religioso exerce praticamente a função de um novo paradigma teológico. No caso do fundamentalismo [...] haverá uma sacralização da letra da Escritura como testemunha fiel da palavra de Deus [...] haverá uma quase sacralização da tradição dogmática da Igreja e uma recusa [...] de colocar no mesmo plano todos os ensinamentos da Igreja, quer se trate dos ensinamentos que dizem respeito à fé como tal ou de um certo número de doutrinas que dependem mais de uma certa tradição teológica (GEFFRÉ, 2004, p. 131; 88-89).

Anthony Giddens (1993) ao tratar da repressão institucional e a questão da sexualidade refere que os espaços para a mobilização são produzidos pela própria expansão da vigilância. Uma sociedade de reflexividade institucional desenvolvida torna possível a existência de formas de engajamento pessoal e coletivo que alteram muito o âmbito das sexualidades.

O sequestro da experiência separa os indivíduos de alguns dos principais pontos de referência moral, através dos quais a vida social foi ordenada [...] Pode-se sugerir que a sexualidade adquire a sua qualidade coercitiva, juntamente com a sua aura de excitação e perigo, do fato de nos colocar em contato com esses campos perdidos da experiência (GIDDENS, 1993, p. 198-199).

Interessante perceber que o ideal buscado por Silas Malafaia em suas pregações é a representação do cristão combativo, cuja vida deve ser um testemunho para a sociedade. Este não deveria dobrar-se às tentações do mundo e aos "modismos" da igreja. Por isso, semelhante à ideia desenvolvida por Karen Armstrong sobre a religiosidade fundamentalista como guerreira e combativa, que cria uma contracultura não utópica para opor-se à sociedade secular (2001, p.9-17), Malafaia sugere a afirmação de que o cristianismo é "contracultura contra a cultura imposta pela sociedade", e que o cristão deve "fazer a diferença".

É inequívoca a posição assumida por Malafaia no sentido de aceitar, acolher e amar para tentar "corrigir", "reorientar", "ajustar". Propõe "curar" a homossexualidade segundo os "seus valores" e "verdade". Seu amor é tutelar, de correção moral. Busca consolidar argumentos que estabeleçam uma correlação valorativa entre "homossexuais" e "bandidos". Objetiva reforçar o vínculo da homossexualidade como sendo um desvio. Sustentando a ideia de que assim como o fenômeno da delinquência atenta e prejudica a sociedade, os homossexuais, sendo um fato social, existem, mas precisam ser corrigidos para que não causem dano ou mal a família, aos bons costumes, a ordem religiosa. ${ }^{5}$

\footnotetext{
${ }^{5}$ Silas Malafaia engajou-se recentemente na tradução, divulgação e promoção do livro do pastor norte americano Louis Sheldon, denominado The agenda. Traduzido para o português como 'A estratégia - o plano dos homossexuais para transformar a sociedade’. O livro foi vendido no catálogo de uma popular empresa de cosméticos o que ensejou uma campanha de boicote e denúncia por parte do movimento LGBT. Disponível em:
} 
A denúncia de uma suposta agenda oculta do movimento pelos direitos civis da população LGBT está sendo incorporada como elemento relevante nos discursos dos líderes evangélicos brasileiros. É uma tática que visa dar legitimidade aos argumentos, retratando ideias, princípios e táticas nascidas do protestantismo de extrema direita protestante norte-americana.

\begin{abstract}
Não se engane a estratégia homossexual é um plano tático para a guerra. Não se trata de uma reunião política pública ou de uma estratégia de marketing: a estratégia que tem sido disseminada pelo lobby homossexual é uma de natureza militar. (...) Esta não é uma batalha contra inimigos estrangeiros, mas contra um inimigo ainda maior: as forças das trevas e legiões de gays e lésbicas furiosas e determinados a abolir a virtude cristã e o julgamento moral de qualquer forma (SHELDON, 2012, p. 267).
\end{abstract}

Ao desqualificar os homossexuais o religioso norte-americano pressupõe que a sua interpretação bíblica e visão moral são paradigmas universais estabelecidos, verdadeiros e fundamentados numa organização social que caracteriza a prática homossexual - e o movimento LGBT - como partes de uma estratégia destinada a destruir o cristianismo.

Os fundamentos da retórica beligerante evidencia a caracterização negativa do "estilo de vida" dos homossexuais como algo doentio e na suposta tentativa dos mesmos de instalar uma sociedade submissa aos seus ditames - algo como um verdadeiro "império homossexual", como denunciou recentemente o senador evangélico Magno Malta (PR-ES), em discurso na tribuna da câmara dos deputados. ${ }^{6}$

A suposta piedade e compreensão amorosa acabam sendo, com efeito, mais uma estratégia retórica para a normatização pastoral e sexual. Silas Malafaia alude de forma contínua e abundante diversas questões inerentes a concepções de gênero, família e sexualidade que acabam não sendo amparadas do ponto de vista do conhecimento científico ${ }^{7}$ e também no âmbito da vivência social, dadas as transformações culturais, sociais, jurídicas e históricas das últimas décadas.

Importante destacar que de acordo com Pierre Bourdieu (1998), a religião forneceria justificativas para a existência humana por produzir um sentido para a vida. Mas esse sentido, necessariamente, precisaria estar contextualizado. Isto porque a produção operada na religião só é

http://www.cartacapital.com.br/sociedade/avon-silas-malafaia-e-a-propagacao-da-homofobia/. Acesso em 22 de Dez. 2015.

${ }^{6}$ Disponível em: http://www12.senado.gov.br/noticias/materias/2012/04/03/magno-malta-ve-tentativa-de-criacao-de2018imperio-homossexual2019-no-brasil. Acesso em: 15 de Dez. 2015.

${ }^{7}$ Uma das respostas mais contundentes para questionar os argumentos levantados por Malafaia foi do biólogo Eli Vieira, mestre e doutorando em genética em Cambridge, no Reino Unido. Através de um vídeo postado na rede social Youtube com mais de um milhão de acessos, o estudioso busca responder ao pastor, mostrando detalhes que comprovam que os argumentos do mesmo estariam manipulados ou equivocados. Disponível em: http://revistaladoa.com.br/2013/02/noticias/cambridge-geneticista-brasileiro-rebate-entrevista-polemica-silasmalafaia. Acesso em: 28 Jun. 2014. 
considerada pela sociedade porque desempenha um papel significativo e estruturante, aceito ou admitido por determinado grupo.

A religião reveste o social com uma aura sagrada e faz a correspondência entre a ordem social e a ordem simbólica. Esta particularidade lhe outorga uma função política estruturante (BOURDIEU, 1998, p. 33). Na perspectiva de Oro (1996), a realidade contemporânea tem exacerbado algumas premissas de cunho fundamentalista, sobretudo pela decorrência da vulnerabilidade social enquanto efeito da globalização e da Modernidade.

Zygmunt Bauman, por sua vez, mostra que "o fascínio do fundamentalismo provém de sua promessa de emancipar os convertidos das agonias da escolha" (1998, p. 228). Segundo o autor, o fundamentalismo tornou-se um remédio radical contra o veneno da sociedade de consumo. É possível afirmar que os indivíduos encontram respostas do que pensar, dizer ou fazer. Seria quase um resgate de valores das tradições ancestrais; algo capaz de fornecer sentido à vida e propiciar uma sensação de controle sobre a incessante chegada do novo.

O discurso com base em algumas diretrizes naturalistas e jurídicas acaba sendo explorado de forma mais enfática (HABERMAS, 2007, p. 235-278). São formulações que incorporam parcela dos princípios dos direitos humanos, realçando ambivalências do ideário dos movimentos sociais (BAJOIT, 2006. p. 251-276) e que motivam itinerários dados pelos "limites" das prerrogativas contidas na proposta de criminalização da homofobia.

$\mathrm{Na}$ visão de Malafaia, o combate à discriminação nos termos do projeto PLC 122, seria incoerente com o próprio ideário do movimento gay, pois tornaria a homossexualidade um atributo comparável à etnia, ao sexo e as múltiplas formas de deficiência física. De acordo com esse raciocínio, mesmo que a sociedade brasileira admitisse essa comparação teria que fornecer meios adequados para melhorar a qualidade de vida dos que se sentem desconfortáveis com a orientação sexual, como ocorre com os portadores de necessidades especiais.

Não se pode ignorar que as controvérsias ocorrem em todas as esferas culturais e que nos processos de reconfiguração do sistema de valores, os religiosos se apropriam das perspectivas científicas e jurídicas que estão mais próximas de suas tradições (MONTERO, 2009). Deve-se acrescentar ainda, que a disputa interna nos próprios segmentos favorece a visão de que os LGBT constituam um movimento social com discursos e demandas pouco unificadas.

A visão propagada por lideranças como Silas Malafaia reforça o ideal de que o legislativo é um espaço no qual os diferentes grupos vão sendo representados na defesa de seus interesses, mas onde as normas legais serão definidas em função dos sistemas de valores da maioria ali representada que é, no caso brasileiro, cristã. 
É engraçado: Ateus podem se expressar. Marxistas também. Humanistas também. Operários também. Filósofos também. Médicos, e vai por aí afora. E por que eu não posso me expressar? Eu sou cidadão. Tenho o direito de me expressar [...] Eu sou cidadão e estou amparado pelo artigo $5^{\circ}$ da Constituição brasileira: é livre a manifestação da opinião (VERDADE GOSPEL, 2012).

Mesmo que se incorpore no debate parlamentar argumentos de natureza jurídica, psicológica, médica e de outros campos do conhecimento, tais argumentos estarão a serviço da convicção de que a sociedade brasileira não deve alterar as normas legais criadas a partir do modelo heterossexual de família. Malafaia parece equiparar as suas prerrogativas eclesiais a um movimento de identidade, na medida em que se baseia na reivindicação de direitos civis para legitimar seu discurso. É uma situação que parece fugir às categorias de análise disponíveis.

\section{Poder, Persuasão e Novos Domínios da (s) Sexualidade (s)}

"Não existe ordem cromossômica homossexual."

"A sociedade é livre para criticar evangélico, criticar católico, criticar deputado. Agora se criticar a prática homossexual é homofobia."

"Casal é homem e mulher, o resto é par."

"Não existe prova científica de que alguém nasce homossexual."

De acordo com Foucault (1988), é a partir do final do século XVII que a sexualidade tornase objeto privilegiado de um saber científico. De acordo com Foucault não procederia a premissa de que o sexo foi silenciado, proibido e reprimido por prejudicar as forças de trabalho durante a ascensão da Revolução Industrial. Para ele nunca houve tanta produção e reprodução discursiva a respeito do sexo como na Modernidade, por meio de instâncias como a Psicanálise, a Biologia, a Anatomia.

\footnotetext{
${ }^{8}$ Palavras proferidas por Silas Malafaia na manifestação em protesto contra a descriminalização do aborto, o casamento gay e pela liberdade de expressão religiosa ocorrida no dia 05 de junho de 2013 na esplanada dos ministérios na capital federal. $\mathrm{O}$ palco montado em frente ao Congresso Nacional atraiu líderes evangélicos, políticos de vários partidos e artistas gospel. O evento organizado por Malafaia foi realizado em um dos dias de maior movimentação no Legislativo. Dezenas de parlamentares ligados à bancada evangélica se revezaram para discursar no ato religioso. Um dos temas mais recorrentes dos oradores do evento foi o casamento entre casais homoafetivos em função da decisão do Conselho Nacional de Justiça (CNJ) que havia determinado aos cartórios do país para que oficializem casamentos entre pessoas do mesmo sexo. Pastores e políticos defenderam que qualquer cidadão deveria ter o direito de se expressar contra as uniões entre homossexuais (PASSARINHO; COSTA, 2013).
} 
Para Foucault a sexualidade estaria em associação direta com as questões inerentes ao poder. $\mathrm{O}$ autor realça algumas peculiaridades na sua teoria sobre o biopoder, resumido como poder sobre a vida. Este biopoder estimularia o aumento da produtividade e realçaria a utilidade dos corpos, das vidas, controlando e regulando algumas práticas, plenificando uma espécie de "adestramento" além de ampliar o sentido das aptidões particulares.

Este biopoder, sem a menor dúvida, foi elemento indispensável ao desenvolvimento do capitalismo, que só pôde ser garantido à custa da inserção controlada dos corpos no aparelho da reprodução e por meio de um ajustamento dos fenômenos de população aos processos econômicos (FOUCAULT, 1988, p. 156).

O discurso de poder proposto por Silas Malafaia trata de um projeto que vem se desenvolvendo para o controle da sexualidade ser entendido como um dos principais dispositivos de poder para o pleno desenvolvimento do capitalismo. Antes de representar um discurso religioso, Malafaia também não deixa de ser um resultado de uma lógica neoliberal que contribui para manter a estrutura normativa a partir da realidade contemporânea e seus mecanismos de poder e persuasão das mentalidades: templos, televisão, música, mídia, política.

Foucault destaca pelo menos duas manifestações históricas acerca do poder que estariam ligadas: um chamado "anátomo-político" que incidiria sobre o corpo humano, buscando torná-lo dócil, controlável e útil, e um poder do "corpo espécie", a saber, um corpo "transpassado pela mecânica do ser vivo e como suporte dos processos biológicos: a proliferação, os nascimentos e a mortalidade, o nível de saúde, a duração da vida" (FOUCAULT, 1988, p. 131).

$\mathrm{O}$ autor destaca que os novos domínios da sexualidade estariam diretamente atrelados as exigências do poder, determinadas ideologias e fatores econômicos. Seria demasiado supor que novos conhecimentos científicos poderiam representar uma suposta neutralidade ou distância dos sentidos inerentes ao poder:

Se a sexualidade se constituiu como domínio a conhecer, foi a partir de relações de poder que a instituíram como objeto possível; e, em troca, se o poder pôde tomá-la como alvo, foi porque se tornou possível investir sobre ela através de técnicas de saber e de procedimentos discursivos (FOUCAULT, 1988, p. 24).

Foucault também faz alusão e busca descrever aquilo que redundaria em "sexualidades periféricas". Com base nesta abordagem e mesmo com toda uma evolução dos conhecimentos científicos, ainda é latente o entendimento de que as práticas homossexuais fazem parte das categorias genéricas de "perversões". Para o autor, até o século XVIII o sexo não heterossexual era legítimo e até aceito socialmente; no entanto, havia aquilo que Foucault entende por "ilegalismo global". Assim, por exemplo, a sodomia fazia parte de uma vivência de crimes contra a lei, junto com a bestialidade e a infidelidade. $\mathrm{O}$ foco se concentrava na relação matrimonial. 
A partir do século XVIII surgem novas categorias de análise, novos recortes, novas práticas classificatórias. São as chamadas perversões: exibicionistas, fetichistas, zoófilas. Os homossexuais passam a ser vistos como indivíduos dotados de uma "natureza singular, própria, única e ambígua" que mereceria ser investigada e melhor compreendida no tocante a sua história, caráter e anatomia; “o sodomita antes era um reincidente, agora o homossexual é uma espécie” (FOUCAULT, 1988, p. 44).

A ideia de uma essência homossexual imutável e determinada no nascimento, defendida por movimentos de apoio aos direitos dos homossexuais, insere-se em grande medida no âmbito deste poder que não busca excluir a sexualidade dos indivíduos, mas sim fixá-la e consolidá-la nos corpos, por meio do entendimento, aceitação e respeito para com o outro. A cada rótulo, a cada domínio, a cada recorte criado pelo conhecimento, multiplicam-se as possibilidades de intervenção do poder. Este mesmo poder que também poderá multiplicar as sexualidades a partir de determinadas nuances e peculiaridades culturais, sociais e religiosas.

Qualquer forma discursiva sempre estará intimamente atrelada a um contexto histórico permeado por variados fatores que condicionam a sua produção e manifestação. Segundo Foucault, em todas as sociedades ocorre esta interferência de procedimentos de controle, seleção ou exclusão. Continuamente vão sendo definidos quais critérios que devem ser legitimados e quais signos devem acompanhar esta elaboração (FOUCAULT, 2009, p. 39).

Não é possível enunciar, aleatoriamente, qualquer coisa, em qualquer local, a qualquer momento. É primordial relacionar o discurso a um contexto mais amplo, ao "sistema de significação em que o indivíduo se inscreve" (FOUCAULT, 2009, p. 109). Mais que uma operação expressiva, o discurso representa "um conjunto de regras anônimas, históricas, sempre determinadas no tempo e no espaço, que definiram, numa dada época, e para uma determinada área social, econômica, geográfica ou linguística, as condições de exercício da função enunciativa" (FOUCAULT, 1972, p. 148).

Foucault destaca que cada enunciado, apesar de singular, está sujeito a se repetir, se transformar, se articular com outros. Neste sentido "diferentes em sua forma, dispersos no tempo, formam um conjunto se eles se referem a um único e mesmo objeto" (FOUCAULT, 1972, p. 43). É importante que haja uma regularidade de "objetos, conceitos, tipos de enunciação ou temas" (FOUCAULT, 1972, p. 43) para definir uma linearidade e coerência dos conceitos ou a consolidação da identidade.

Ao valer-se de uma retórica científica, que visa a legitimar a posição de que a sexualidade é "adquirida" ou "imposta", não inata, Silas Malafaia obedece a uma lógica clara e direta: se o pastor 
aceita a ideia de uma sexualidade definida ou fortemente influenciada por fatores incontroláveis, como a carga genética, a proposta de conversão torna-se inócua e ficaria inviabilizada. Desta forma, é estratégica a escolha de uma argumentação de cunho não religioso.

Para Foucault os discursos são "elementos ou blocos táticos no campo das correlações de poder" (FOUCAULT, 1988, p.97). Ainda que discursos semelhantes possam circular entre estratégias opostas é no embate que ambos se valem dos mesmos ritos de produção de discurso recorrem a pesquisas, estatísticas, teorias de pesquisadores de renome, títulos, nomenclaturas.

Esta "guerra santa" contra o reconhecimento dos direitos das minorias tem muito a ver com os direitos de reconhecimento, nos termos de Nancy Fraser (1997), com a noção de justiça social, pois se trata de erradicar conceitos negativos relacionados aos grupos sociais historicamente discriminados. Ou seja, não basta perseguir a igualdade de renda ou garantir políticas sociais (os direitos de redistribuição): é também preciso enfrentar preconceitos e promover positivamente determinadas populações, em um processo de valorização cultural e combate a estigmas (GOFFMANN, 1989). Um ideal antagônico à crença e à prática de lideranças evangélicas como do principal dirigente da Associação Vitória em Cristo, Silas Malafaia.

Em certa medida, líderes religiosos têm o direito de expressar as posições para os seus fiéis da forma como considerarem adequado. A dificuldade surge quando um líder como Malafaia em suas declarações contundentes atua para que outras pessoas defendam uma visão conservadora confundindo liberdade religiosa e de expressão com uma espécie de guerra contra a diversidade. São ações que alimentam a intolerância, monopolizam uma determinada "verdade" e abrem as portas para uma religiosidade eivada de ódio, ignorância e repleta de incompreensões.

\section{Considerações Finais}

A rejeição da união civil entre pessoas do mesmo sexo e a criminalização da homofobia favorece mecanismos de produção das desigualdades. O argumento da "liberdade de crença" oculta estratégias insidiosas de construção da superioridade moral da heterossexualidade e desqualifica a diversidade sexual, na maioria das vezes colocando-a no âmbito dos desvios, das patologias, das aberrações (NATIVIDADE, 2006). A homofobia religiosa se expressa na reprodução de estereótipos que desqualificam a diversidade sexual realçando o caráter "pecaminoso", hostil e perigoso da homossexualidade.

Os embates apresentados revelam a complexidade das discussões acerca da homofobia e as formas correlatas de violência que incidem sobre populações cuja conduta é dissidente da heterossexualidade. Ao atribuir à homossexualidade um caráter ameaçador e lutar contra os direitos 
das pessoas LGBT, grupos religiosos e personalidades como Silas Malafaia, reproduzem imagens negativas, apelam a estigmas e estereótipos da diversidade sexual.

Vale destacar que construções do gênero e do desejo que sejam destoantes da norma hegemônica são marcadas como diferenças indesejáveis, reiterando uma obrigatoriedade de uma conduta heterossexual. $\mathrm{O}$ desprezo social e religioso dirigido a aqueles que não se enquadram nesta perspectiva revela processos de formação da identidade que são assentados na valorização de si mesmo e pela consequente desqualificação do outro (ERIBON, 2008).

Importante observar que sob uma perspectiva sociológica, essa relação depreciativa acentua a produção de assimetrias sociais, desigualdades de oportunidades, diferenças de status, obstrução de direitos, estereótipos negativos e processos de estigmatização. A homofobia religiosa se fortalece quando opera discursos baseados em valores religiosos que realçam táticas plurais de desqualificação e controle da homossexualidade. Ela não se manifesta somente nas percepções e juízos morais, mas envolve formas de atuação em oposição à visibilidade e reconhecimento de minorias sexuais, tanto na esfera pública como privada.

Para não ser subjugado pela retórica do preconceito e a violência simbólica, é necessário exercitar a crítica pública. É com ela que talvez seja possível encontrar caminhos para vivenciar a alteridade, uma consciência de direitos humanos e de reconhecimento das violências sofridas por minorias e grupos vulneráveis em uma esfera pública ainda muito refratária ao preconceito.

\title{
THE LEGIMITAZATION OF INTOLERANCE IN THE STATEMENTS OF PASTOR SILAS MALAFAIA
}

\begin{abstract}
The logic that sets the composition of the neopentecostal doctrinal framework assumes a new discursive mapping marked by the fragmentation of subjectivity. It gives rise to a kind of understanding capable of embracing some sort of religiosity that sees the world in permanent tension between the spirits or demons that cause evil and disorder and the gods associated with the good and the order. The neopentecostal religion is organized and shaped, to a larger extent, upon an accusatory speech that derives from its capacity to touch, reach, incorporate and redirect some elements found in the symbolic universe of reference of the Brazilian population. Religious intolerance takes shape through a spiritual warfare no longer limited to the spiritual realm: it is witnessed on a daily basis and worsened by belligerent speeches, especially those regarding homosexuality and abortion such as the ones delivered by Pastor Silas Malafaia. This paper intends to deepen the perspective of human rights, the issues inherent to minorities and vulnerable groups, the prejudice raised by symbolic violence and the rhetoric of prejudice supported by public criticism with fundamentalist nuances.
\end{abstract}

Keywords: Neopentecostalism; Intolerance; Silas Malafaia. 


\title{
LA LEGITIMACIÓN DE LA INTOLERANCIA EN LAS DECLARACIONES DEL PASTOR SILAS MALAFAIA
}

\begin{abstract}
Resumen
La lógica que configura a composición del marco doctrinario neopentecostal presupone una nueva cartografía discursiva marcada por la fragmentación de las subjetividades. Implica uma comprensión capaz de abarcar una religiosidad que concibe el mundo en tensión permanente entre los espíritus o demonios causantes del mal y de la desorden y los dioses asociados al bien y la orden. La religiosidad neopentecostal se articula y se amolda, en gran medida, con base en un discurso acusatorio que se deriva de esa su capacidad de tocar, alcanzar, incorporar y adaptar algunos elementos presentes en el universo simbólico de referencia para la población brasileña. La intolerancia religiosa se delinea a través de la batalla espiritual ya no más circunscrita a la esfera espiritual, pero, de ordinario, agravada por los discursos beligerantes, sobretodo en relación a la homosexualidad y al aborto, como los protagonizados por el pastor Silas Malafaia. El artículo pretende profundizar en la perspectiva de los derechos humanos, las cuestiones inherentes a las minorías y grupos vulnerables, el prejuicio suscitado por la violencia simbólica y la retórica del prejuicio basado en la crítica pública con matices fundamentalistas.
\end{abstract}

Palabras clave: Neopentecostalismo; La intolerancia; Silas Malafaia.

\section{REFERÊNCIAS}

ARMSTRONG, K. Em nome de Deus - o fundamentalismo no Judaísmo, no Cristianismo e no Islamismo. São Paulo: Companhia da Letras, 2001.

BAJOIT, G. Tudo Muda. Proposta Teórica e Análise da Mudança Sociocultural nas Sociedades Ocidentais Contemporâneas. Ijuí: UNIJUI, 206.

BEATY, D. M. A Essência do Estado de Direito. São Paulo, Martins Fontes, 2014.

BOURDIEU, P. A economia das trocas simbólicas. São Paulo, Perspectiva: 1998.

BUTLER, J. Problemas de gênero: feminismo e subversão da identidade. Rio de Janeiro: Civilização Brasileira, 2003.

OlIVEIRA, C. R. (Org.); PICHLER, N. (Org.) CANABARRO, R. P. (Org.). Filosofia e Homoafetividade. Passo Fundo: Méritos, 2012.

CASTELLS, M. Redes de indignação e esperança: movimentos sociais na era da internet. São Paulo: Zahar, 2013.

CÉSAR, M. C. Entre a Cruz e o Arco-Íris. A Complexa Relação dos Cristãos com a Homo Afetividade. Belo Horizonte: Gutenberg, 2013. 
CUNHA, C. V.; LOPES, P. V. L. Religião e Política: Uma Análise da Atuação de Parlamentares Evangélicos sobre Direitos das Mulheres e de LGBTs no Brasil. Rio de Janeiro: Fundação Heinrich Böll, 2013.

De Cambridge, geneticista brasileiro rebate entrevista polêmica de Silas Malafaia. Revista lado a. Disponível em: http://revistaladoa.com.br/2013/02/noticias/cambridge-geneticista-brasileirorebate-entrevista-polemica-silas-malafaia Acesso em 28 de Jun. 2014.

EMMERICK, R. Religião e Direitos Reprodutivos. O Aborto como Campo de Disputa Política e Religiosa. Rio de Janeiro: Lumen Juris, 2013.

ERIBON, D. Reflexões sobre a questão gay. Rio de Janeiro: Companhia de Freud, 2008.

Evangélico e presidente da ABGLT debatem homofobia. Câmara dos Deputados. Disponível em: http://www2.camara.leg.br/camaranoticias/noticias/DIREITOS-HUMANOS/197965-

EVANGELICO-E-PRESIDENTE-DA-AGLBT-DEBATEM-HOMOFOBIA.html Acesso em 23 de Jun. 2014.

FRESTON, P. Breve História do Pentecostalismo no Brasil. In: ANTONIAZZI, Alberto. Nem anjos, nem demônios. Petrópolis: Vozes, 1996. p. 67-99.

FOUCAULT, M. A Ordem do Discurso. São Paulo: Edições Loyola, 2009. História da Sexualidade I: A vontade de saber. Rio de Janeiro: Edições Graal, 1988. Arqueologia do Saber. Petrópolis: Vozes, 1972.

FORBES. Disponível em: http://noticias.uol.com.br/internacional/ultimasnoticias/2013/01/18/forbes-lista-os-seis-lideres-milionarios-evangelicos-no-brasil.htm. Acesso em: 03 de Dez. 2015.

GEFFRÉ, C. Crer e interpretar. A virada hermenêutica da teologia. Petrópolis: Vozes, 2004.

GOFFMANN, E. A Representação do eu na vida cotidiana. Petrópolis: Vozes, 1989.

GUERRIERO, S. Novos Movimentos Religiosos. O Quadro Brasileiro. São Paulo, Paulinas, 2006.

HABERMAS, J. Entre Naturalismo e Religião: Estudos Filosóficos. Rio de Janeiro: Tempo Brasileiro, 2007.

HOMOFOBIA. Disponível em: http://www.cartacapital.com.br/sociedade/avon-silas-malafaia-e-apropagacao-da-homofobia/. Acesso em 22 de Dez. 2015.

JURKEWICZ, R.S. Cristianismo e homossexualidade. In: GROSSI, M. P. (org.). Movimentos Sociais, educação e sexualidade. Rio de Janeiro: Garamond, 2005.

LOURO, G. L. Gênero, Sexualidade e Educação: uma perspectiva pós-estruturalista. Rio de Janeiro: Vozes, 2007. 
MACHADO, M. D. C. Aborto e Atvismo religioso nas eleições de 2010. Revista Brasileira de Ciências Política 7, 2012. p.25-37.

MACHADO, M. D. C.; PICOLO, F. Religião e Homossexualidade. Rio de Janeiro: Fundação Getúlio Vargas, 2011.

MALAFAIA, S. Minhas Experiências de Vida. Editora Central Gospel, Rio de Janeiro, 2012.

União homossexual atacada por Malafaia. Disponível em: http://veja.abril.com.br/noticia/brasil/malafaia-ataca-uniao-homossexual-e-gera-reacao-nas-redessociais Acesso em: 25 de Jun. 2014.

Magno Malta e a Criação de Império Homossexual. Disponível em: http://www12.senado.gov.br/noticias/materias/2012/04/03/magno-malta-ve-tentativa-de-criacaode-2018imperio-homossexual2019-no-brasil Acesso em: 15 de Dez. 2015.

MARIANO, R. Neopentecostais: Sociologia do Novo Pentecostalismo no Brasil. São Paulo: Loyola, 1999.

Milhares Protestam em Brasília. Disponível em: http://g1.globo.com/politica/noticia/2013/06/milharesprotestam-em-brasilia-contra-aborto-e-casamento-gay.html_Acesso em: 18 de Dez. 2015.

MONTERO, P. Jürgen Habermas: religião, diversidade cultural e publicidade. Novos Estudos CEBRAP, n. 84, p. 199-213, 2009.

NATIVIDADE, M. Uma homossexualidade santificada? Etnografia de uma comunidade inclusiva pentecostal. Religião e Sociedade, v. 30, n. 2. Rio de Janeiro? ISER/ UERJ, 2010.

"Homossexualidade, gênero e cura em perspectivas pastorais evangélicas”. Revista Brasileira de Ciências Sociais. Vol.. 21, n. 61, São Paulo, Edusc. 2006.

Nota de Conselho de Psicologia é direcionada a Silas Malafaia. Disponível em: http://www.tribunahoje.com/noticia/54446/brasil/2013/02/07/nota-de-conselho-de-psicologia-edirecionada-a-silas-malafaia.html Acesso em 22 de Jun. 2014.

ORO, I. P. O outro é o demônio; uma análise sociológica do fundamentalismo. São Paulo: Paulus, 1996.

PASSARINHO, N.; COSTA, F. Milhares protestam em Brasília contra aborto e casamento gay. G1. Disponível em: http://g1.globo.com/politica/noticia/2013/06/milhares-protestam-em-brasilia-contra-aborto-ecasamento-gay.html Acesso em: 29 de Jun. 2014.

PLC 122. Disponível em: http://www.plc122.com.br/plc122-paim/\#ixzz35rz6A2A2 Acesso em: 20 de Dez. 2015. 
RONCAGLIA, D. Malafaia chama de "absurda" a ação que o acusa de homofobia. Folha UOL. Disponível em: http://www1.folha.uol.com.br/poder/2012/02/1050402-malafaia-chama-deabsurda- a-acao-que-o-acusa-de-homofobia.shtml Acesso em: 20 de Jun. 2014.

TOLIPAN, H. Absurdo! De Silas Malafaia no "De Frente com Gabi"” Amo Gays como Amo Bandidos'. Jornal do Brasil. Disponível em: http://www.jb.com.br/heloisatolipan/noticias/2013/02/03/absurdo-de-silas-Malafaia-no-de-frente-com-gabi-amo-gays-comoamo-bandidos/ Acesso em 18 de Jun. 2014.

RIOS, R. R.; GOLIN, C.; LEIVAS, P. G. C. Homossexualidade e Direitos Sexuais: Reflexões a partir da decisão do STF. Porto Alegre: Sulina, 2011.

SANTOS, B.S. Se Deus fosse um Ativista dos Direitos Humanos. São Paulo: Cortez, 2014.

SHELDON, L. P. A estratégia (The Agenda): O Plano dos Homossexuais para transformar a Sociedade. Rio de Janeiro: Editora Central Gospel Ltda. 2012.

VERDADE GOSPEL. Pastor Silas Malafaia responde Fernando Haddad. Disponível em: https://www.youtube.com/watch?v=Mhi8JMzoyFA. Acesso em: 10 de Dez. 2015.

Disponível em: Dia Nacional de Valorização da Família. http://www.verdadegospel.com/nesta-terca-feira-pr-silas-discursara-pela-valorizacao-da-familiaconfira/ Acesso em: 10 de Dez. 2015.

VITÓRIA EM CRISTO. Disponível em: http://www.vitoriaemcristo.org/_gutenweb/_site/gw-prsilas Acesso em 05 de Dez. 2014.

Data de recebimento: 02/03/2016

Data de aceite: $28 / 07 / 16$

\section{Sobre o autor:}

Celso Gabatz possui bacharelado em Teologia - Faculdades EST, bacharelado e licenciatura em Sociologia - UNIJUI. É Mestre em História - UPF e Doutorando em Ciências Sociais - UNISINOS. Endereço eletrônico: gabatz@uol.com.br 